\title{
Torres vigía o de guaita en la provincia de Castellón
}

\author{
Josefina Montoliu Ripollés
}

\section{Introducción}

En nuestra costa, quedan torres vigía o de defensa, algunas bien conservadas, algunas en ruinas y abandonadas, mientras que otras han desaparecido. Estas torres se construyeron durante los siglos XVI y XVII, con la misión de vigilancia y de protección de los habitantes de las poblaciones de la costa ante los ataques de los piratas berberiscos.

Toda la costa se podía comunicar de torre en torre y estas, con los castillos, para dar la alarma sobre la presencia de los piratas.

\section{Torres desaparecidas}

Algunas han desaparecido, por la desidia de los habitantes o de las autoridades, como son:

\section{Torre de Beniesma, Moncofar}

Fue construida antes de la expulsión de los moriscos en 1609 y se encontraba en la desembocadura del río Belcaire, en la playa de Moncofar.

\section{La Torre del Mar, Grao de Castellón}

Situada frente a la actual escollera poniente, a unos 50 metros de la escollera donde había restos de los cimientos de la torre del Mar de Castellón. Construida en el siglo XVI como torre de vigía ante las incursiones de los piratas berberiscos entre la olla de Benicasim y la otra torre situada en la desembocadura del río Mijares.

\section{San Julián en Benicasim}

Se comunicaba visualmente con la torre de San Vicente. Se encontraba a una milla náutica al noreste del torreón de San Vicente, siguiendo la línea costera, frente al mar, pegada al límite con el término municipal de Oropesa.

\section{Torres de castillos o fortalezas}

Torres que pertenecían a los castillos o fortalezas:

Castell Vell, ermitorio de la Magdalena, Castellón

En el monte de la Magdalena, a la que se accede por la carretera CV-147, se encuentran los restos de este castillo, que es el origen de la ciudad. Es una estructura militar islámica por el sistema tapial calicostrado empleado en la construcción de las murallas. El castillo está de forma escalonada adaptándose al terreno. Se compone de tres recintos: el superior es la alcazaba, de forma poligonal; la zona intermedia es el albacar o patio de armas, más grande y con tres torres, ya que el campanario de la ermita es una torre, y en el tercer recinto aparecen restos de una torre cuadrangular en la zona noroeste.

\section{Atalaya de Montornés, Benicasim}

Forma parte del castillo de Montornés, en el extremo oeste, sobre una cima de 500 metros de altitud. 
El origen del castillo parece ser del siglo $\mathrm{x}$, construido por los árabes sobre una construcción de origen romano. Tuvo su importancia para la defensa de la zona por su situación, ya que domina un gran espacio marítimo. Es una de las dos torres del castillo que queda en pie. Su forma es cilíndrica, construida en piedra caliza, y vigila el acantilado situado a las espaldas del castillo (figura 1).

Se puede llegar a ella por la autopista A-7, a 4 kilómetros de Benicasim, en las cercanías del convento de carmelitas llamado Desierto de las Palmas.

\section{Torre de Montornés, Benicassim}

Forma parte del sistema defensivo del castillo de Montornés y está sobre una escarpada cima de unos 500 metros de altura en el extremo oeste del despoblado de Montornés.

Es una torre de planta cuadrada, que domina todo el valle y la costa. Se encuentra en estado de ruina.

Se puede llegar a ella por la autopista A-7, a 4 kilómetros de Benicasim, en las cercanías del convento de carmelitas llamado Desierto de las Palmas.

\section{Fortaleza de Albalat, Cabanes}

La construcción de la ermita fue iniciada a finales del s. XIII, dedicada a la Virgen de la Asunción, y luego fortificada, ante la amenaza de los piratas, en el s. XIV.

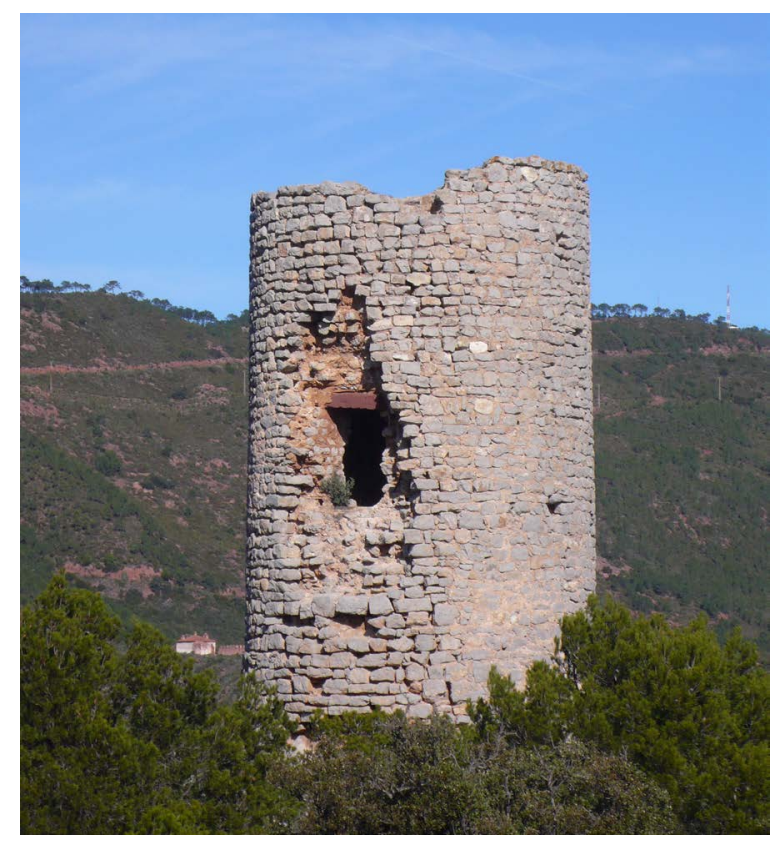

Figura 1. Atalaya de Montornés. Benicasim
En la fortificación se elevó un muro hasta la parte de los tejados, convirtiéndose esta en una terraza almenada. Sobre la capilla se levanta la torre, rematada de forma almenada. Tiene dos dependencias de vigilancia y guardia. Es de mampostería y sillería en los ángulos.

Desde aquí, se observan las ruinas del castillo de Albalat, en la cima de la montaña a cuyos pies se encuentrala fortaleza. Se encuentra muy cerca dela autopista A-7, pasadas las localidades de Venta de San Vicente y El Ventorrillo, en dirección a la localidad de Torreblanca.

Desde la misma iglesia fortaleza sale el denominado camino de las torres, que nos lleva a la torre dels Gats y torre Carmelet, que se encuentran a $1,5 \mathrm{~km}$ aproximadamente, en dirección a Castellón.

\section{Torres rurales}

Las torres defensivas de carácter rural servían de refugio a los campesinos cuando llegaban los piratas a la costa. Eran construcciones de planta cuadrangular, muros de mampostería con esquinas de sillarejo, cubierta inclinada de una vertiente partida y remates a modo de almenas o merlones en sus dos testeros, que culminan con un sillar en forma de pirámide. Algunos ejemplos de torres de este tipo son:

\section{Torre de la Regenta, Alquerías Niño Perdido}

Colindante con el camí de la Ratlla de Vila-real, en un recinto cerrado, dentro de una propiedad privada. Su planta es rectangular y su altura de 11,20 metros. Consta de planta baja, dos pisos altos con saeteras y una terraza almenada.

\section{El Fadrí, Castellón}

Fue construida en la tercera década del siglo xv, como torre vigía, para la agrícola villa de Castellón. La torre tendría una altura de ocho metros, de planta octogonal; consta de tres plantas, aunque luego se serviría de ella para elevarla a mayor altura y utilizarla como campanario.

Está situada en la plaza Mayor, en el centro de la ciudad, junto a la iglesia de Santa María la Mayor. 


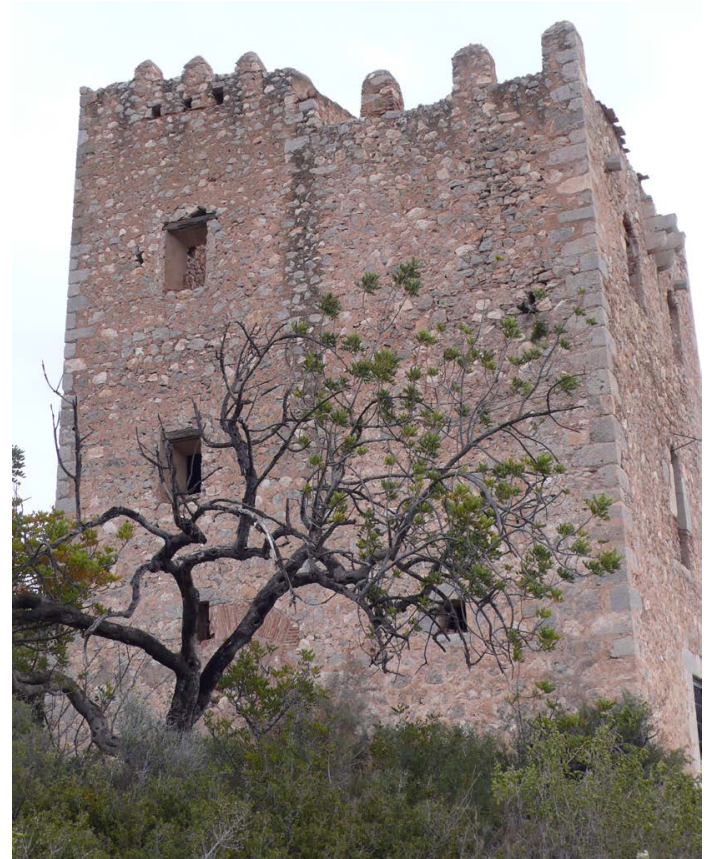

Figura 2. Torreta Alonso, Castellón

\section{La Torreta Alonso, Castellón}

Está ubicada en el macizo del Maestrazgo, a poca distancia de Castellón, en la partida del Bovalar.

La torre está a unos 90 metros de altitud, desde donde se divisa la costa. La fachada principal está orientada al este y tiene como acceso una puerta adintelada y jambas de sillería (figura 2). Sobre la puerta hay una ventana rectangular en el primer piso y, sobre esta, dos ventanas mayores en la planta superior rematadas con arcos. Dispone de varias pequeñas aberturas en sus paramentos.

De características parecidas son las torres cercanas entre sí: torre del Carmelet, torre del Carmen y torre dels Gats, situadas en la Ribera de Cabanes. Son de planta cuadrada y tres plantas. Poseen garitas redondas en dos esquinas opuestas. Las torres son de mampostería, con las esquinas y los recercados de la puerta y ventana de sillares.

\section{Torres en la playa}

\section{Torre del Mar, Burriana}

Torre vigía construida en el siglo xvi para la defensa de las costas. Ubicada en la zona de El Clot, a unos 150 metros de la playa, concretamente en el Grao y junto a la desembocadura del río Seco, en medio de un descampado rodeado de residencias veraniegas.

Tiene una altura de 10,20 metros y consta de dos plantas, dado que el tercer piso ya no existe. Es de base cuadrada.

En la planta baja se encuentran un pozo del que se abastecían y un pesebre en el que se ofrecía agua y comida a los caballos de los soldados, con tres aspilleras para la defensa. En la segunda planta, hay ventanas saeteras, con una acusada inclinación oblicua, especialmente las del lado del Clot.

\section{Torre de San Vicente, Benicasim}

A mediados del s. XVI, por orden de las Cortes de Monzón, se construyó la torre para la defensa de la llamada Olla de Benicasim, debido a los continuos ataques de los corsarios y berberiscos.

La torre es de planta cuadrada, construida en mampostería y angulares de sillar, un matacán aspillerado y, en las esquinas de la parte que da al mar, en la parte superior, dos torrecillas circulares. Tiene una puerta de acceso a metro ochenta del nivel del suelo. Estaba provista de (Aula Militar, 2013):

un cañón de hierro de seis libras de calibre con su cureña de campaña, un atacador cuchara, sacatrapos, dos cavesales, dos cuñas de miras, dos espeques y doce balas para el cañón. Dos pasamuros, sinco mosquetes, sinco frascos, sinco horquillas, dos botavanes, siento y cuarenta bolas de mosquete, pólvora quinze libras, y cuerda mecha, cuatro varas y servían los soldados siguientes: Joseph Doménech, alcayde, Manuel Llopis y Pasqual Guiral, soldados de a cavallo, Joseph Prats y Lois Rovira, soldados de a pie.

Comunicaba visualmente con la torre Colomera de Oropesa, con las torres del castillo de Montornés y con otras dos torres hoy día desaparecidas que estaban junto al mar: al sur, la torre del Grao $y$, a levante, en un altozano, la torre que se llamaba de San Julián.

Se accede desde el casco urbano de Benicasim, en dirección al mar, a través de la calle de la Torre, en la avda. Ferrandis Salvador.

\section{Torre del Rey, Oropesa}

Se encuentra en la Punta de les Llances, junto al faro de Oropesa. La costa de Oropesa, con sus en- 


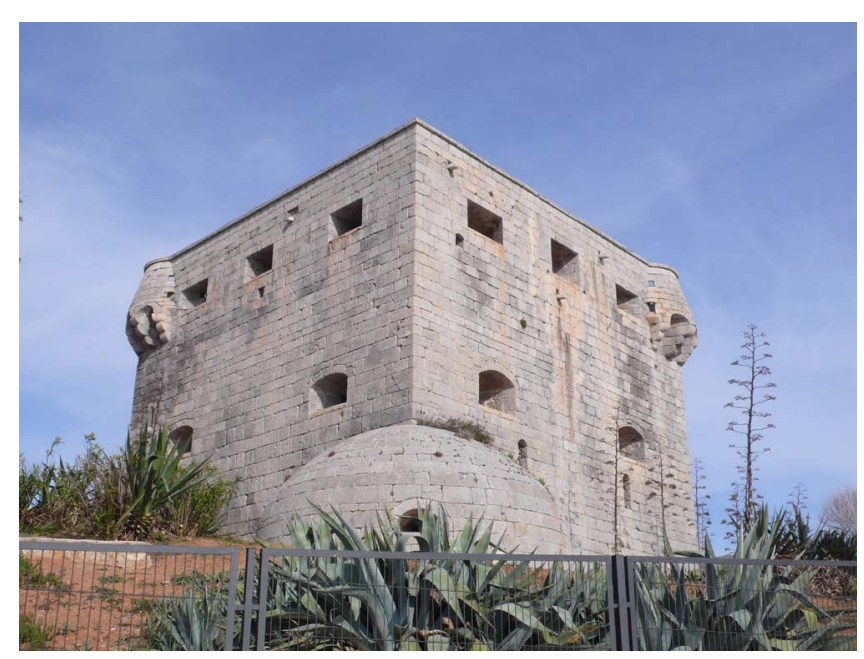

Figura 3. Torre del Rey, Oropesa

senadas, era un buen refugio para los piratas que asaltaban las naves de los mercaderes y de los moros. Fue construida en estilo renacentista en el siglo XVI, sobre otra torre más antigua.

En 1534, el berberisco Barbarroja desembarcó en el cabo de Oropesa, apoderándose del fuerte. Entonces, el conde de Cervellón, señor de la villa de Oropesa, reforzó la torre aumentando los muros de la planta baja y construyó las caponeras. La torre está formada por dos, una dentro de la otra: la vieja o medieval de 1412 y la nueva de 1534 (figura 3).

La torre nueva se construyó sobre la vieja y está formada por cuatro plantas. La planta baja es la misma que la de la torre vieja, añadiendo dos caponeras, con tres troneras cada una, y se ampliaron los muros, un pequeño vestíbulo con tres vanos, el de la entrada, el que comunica con las caponeras y al portal y el que da acceso a las escaleras. El primer piso está dividido en dos salas, con chimenea para la habitabilidad del los soldados. La planta alta, al descubierto, es la destinada a la defensa. Sus troneras tienen una gran visión y, en los huecos de las bóvedas, había dos aljibes. Es uno de los pocos ejemplos que se conservan de arquitectura militar renacentista.

\section{Torre La Sal, Cabanes}

Se encuentra a unos 100 metros de la playa, a unos $12 \mathrm{~km}$ del municipio por la CV-146 hacia la Ribera, junto a la misma playa, y a $3 \mathrm{~km}$ al norte de Oropesa del Mar y al lado del parque natural del Prat de Cabanes.
Es de planta cuadrada, de unos seis metros de lado. Posee sillares en las esquinas y mampostería irregular en las otras paredes. La puerta es de arco de medio punto, con tres peldaños en la fachada orientada a Oropesa. Sobre la puerta y en otra esquina, hay un matacán.

\section{Torre Nostra o Torre Nova, Torreblanca}

En su origen, fue una torre aislada y se encuentra en el antiguo núcleo pesquero de Torrenostra, junto al paseo marítimo y muy próximo al parque natural del Prat. Desde 1875, llegaron las primeras familias y edificaron las primeras casas tomando la alineación de la torre, frente al mar.

Controlaba el acceso desde el mar y fue totalmente restaurada en el 2007. Es de planta cuadrada de 8,70 metros de lado y 9 metros de altura. Posee muros de un metro de espesor de mampostería con mortero de cal con sillares canteados en las esquinas $\mathrm{y}$ huecos.

La piedra empleada es caliza y arenisca. Las piedras areniscas constituyen parte de las esquinas (cada tres hiladas), así como los sillares de la cornisa. El resto de las esquinas lo forma la piedra caliza. Poseía matacanes cilíndricos en las cuatro esquinas y otro sobre la puerta de entrada. Tiene cuatro plantas: planta baja, dos plantas superiores y cubiertas. En el interior disponía de escalera de caracol, situada en el extremo oeste.

La puerta abierta hacia Oropesa, hoy tapiada por una construcción adosada, era de madera, acorazada con planchas de hierro. Poseía dos ventanas por lienzo y las inferiores aspilleradas.

\section{Torre de doña Blanca de Cardona, Torreblanca}

El origen del nombre de Torreblanca es objeto de controversia; según la opinión más extendida, fue por la torre del Marqués, que se supone que fue heredada por doña Blanca de Cardona, que pudo ser muy bien doña Blanca de Aragón, hija del infante Ramón Berenguer y nieta, por tanto, de Jaime II de Aragón.

Estos datos y referencias concuerdan con que doña Blanca pudo dar nombre a la torre y esta, a la villa.

Es un edificio medieval de planta cuadrangular y cuatro plantas, almenado con una pequeña arca- 
da y una puerta de entrada de arco de piedra de medio punto, blindada con gruesos clavos. Sobre esta fachada se encuentran también cuatro ventanas rectangulares. En la fachada opuesta también se aprecia la existencia de varias ventanas de la misma proporción. Posee una garita redonda en su esquina noroeste y un matacán sobre la puerta de entrada, a la altura del tercer piso.

La propiedad se ha mantenido lindando, de una parte, con la montaña, la sierra, y, de otra, con el camino de las Marjales. Se llega a ella por el camino rural de l'Atall.

\section{Torre de Cap i Corb, Alcalà de Xivert}

Fue construida en 1427. Su planta es cuadrangular y su alzado es de 13 metros, con sillería en los cuatro ángulos que conforman las paredes de cerramiento, con un grosor de 2 metros cada una. Consta de una planta baja en la que se abre la puerta original, con arco de piedra en forma de medio punto; una planta media, con ventana sobre la vertical de la puerta anterior, y una planta superior o cubierta en la que se conservan todavía las ménsulas de la antigua corsera que tenía la torre (matacán corrido).

Posee unos dispositivos para uso de ballestería de trueno. Una escalera interior de caracol, situada en el ángulo nordeste del edificio, permite el acceso desde la planta baja a la media y a la azotea.

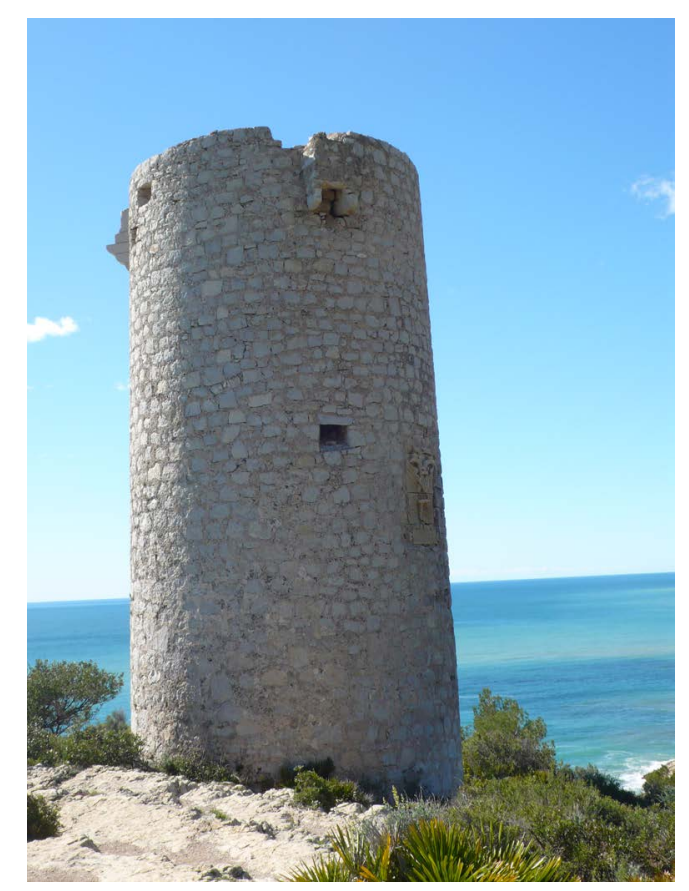

Figura 4. Torre Ebrí, Alcalà de Xivert
En la actualidad, está convertida en propiedad particular. Se comunicaba visualmente con Torrenostra, en el término municipal de Torreblanca, y con la torre Ebrí, de la sierra de Irta.

De fácil acceso, se puede llegar desde el camino de Cap i Corp o bien por el camino de l'Atall, cruzando la desembocadura del río. Desde este lugar, se puede disfrutar de las playas que llevan el nombre de la torre.

\section{Torres de vigía}

Eran solo de vigilancia. Estaban defendidas de forma permanente por dos soldados de a pie y dos soldados a caballo o atalladors, encargados de recorrer el camino o atajo que había entre las torres para mantener la comunicación entre ellas.

\section{Torre de la Corda y la Colomera, Oropesa}

Construidas para apoyar a la torre del Rey, para la defensa del litoral. Son de planta circular, con forma troncocónica, construida en mampostería y, alrededor de su perímetro, hay una serie de troneras o ventanas pequeñas desde las que se vigilaba todo el alrededor. La puerta está en alto, para dificultar el acceso al enemigo, entrando a su interior mediante una cuerda. Se puede llegar a ellas por la senda verde, que transcurre paralela al mar, desde Benicasim a Oropesa.

\section{La Torre Ebrí, Alcalà de Xivert}

En plena sierra de Irta, a 499 metros de altura sobre el nivel del mar, cuyos orígenes parecen remontarse al siglo Xvi. Desde una altura de 8,5 metros, se divisa Peñíscola, Alcalà de Xivert, Torrenostra, el Desierto de Las Palmas y Alcossebre y, en días claros, se divisa el Delta del Ebro.

Esta construcción formaba parte del sistema de alerta y vigía del castillo de Xivert. La torre, construida de mampostería, es de forma tronco conoidal de 5,50 metros de diámetro en la base y 5,05 metros en la parte más alta. Su altura es de 8,50 metros y el grosor de las paredes de 1 metro en la base y 0,50 metros en la coronación (figura 4).

Posee una ventana orientada al mar, recercada de piedra de sillería y sobre la que se conservan los restos de un matacán. Existen otras cuatro venta- 


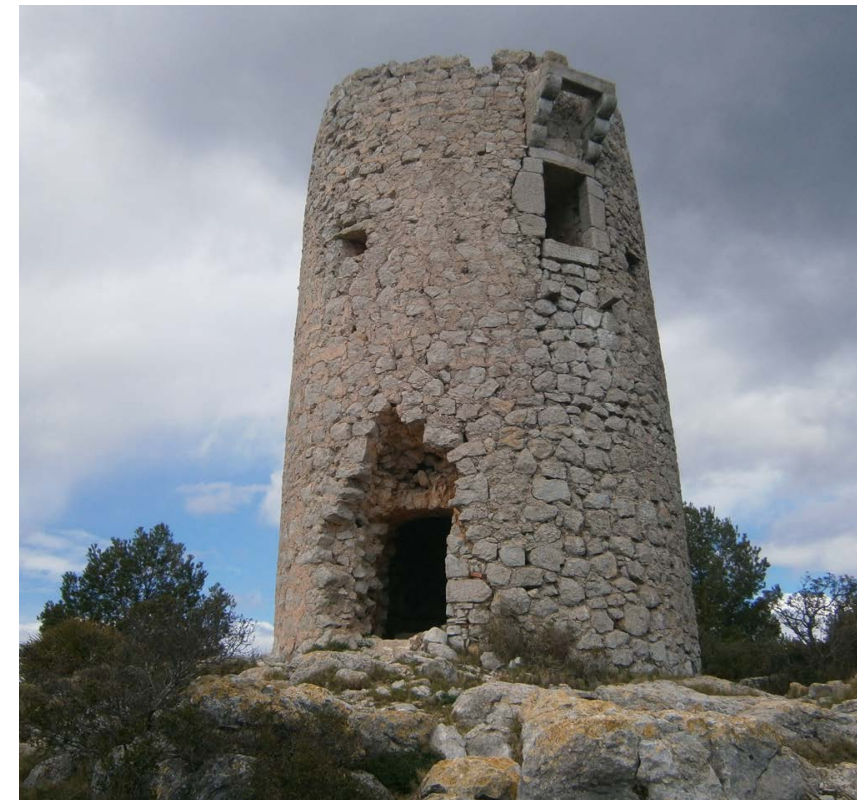

Figura 5. Torre Badum, Peníscola

nillas o aspilleras a la altura de la ventana y otra en la terraza superior. En el interior, la planta baja era destinada a los caballos y existió un primer piso, hoy desaparecido, para los guardias. La puerta de arriba es el acceso, a la que se llegaba con una escalera de cuerda y estaba protegida por una ménsula.

Su acceso se efectúa a través de la carretera de El Pinar y desde las inmediaciones del vial que lleva a la ermita de Sta. Lucía y S. Benet, a través del camino existente, a unos $2,5 \mathrm{~km}$ aproximadamente.

\section{Torre Badum, Peñíscola}

Se sitúa en la costa de la sierra de Irta y a escasamente a $6 \mathrm{~km}$ de Peñíscola, entre el barranco del Volante y la playa del Pebret. Al salir de Peñíscola, hay que tomar la carretera asfaltada en dirección a la sierra del Irta y calas del Pebret. Después de unos $4 \mathrm{~km}$, esta carretera se desvía hacia la izquierda en un tramo de tierra, situado a solo dos kilómetros de la torre.

No se sabe con certeza si pertenecía al castillo de Xivert o al castillo de Peñíscola.

Fue construida en el año 1554. Es de planta circular, de 11 metros de altura, cuerpo troncocónico, con un diámetro de $5,75 \mathrm{~m}$ en la base y de 5,25 $\mathrm{m}$ en la parte superior (figura 5). Tiene unas pequeñas ventanas en la parte superior y una puerta en altura, a unos $6 \mathrm{~m}$, que da acceso a una sala circular. En la fachada que da al oeste, hacia el camino del Pebret, se distingue un escudo del reino de Valencia, de la época del rey Carlos V, presidida por el águila bicéfala de la casa de los Austrias. En caso de alarma, se encendía una enorme hoguera para alertar a la fortificación de Peñíscola de las posibles invasiones que viniesen del sur. 


\section{Referencias}

AulaMilitar (2013). Inventario de 1728 de las torres distrito de Castellón. http://www.aulamilitar.com/INVENTARIO1728.hts?ID_SESION=XSTXFUUFGHFLXRWRMMTT 20/07/2013

Ayuntamiento de Castellón (2013). Castell Vell. http://www.castellonturismo.com/cultura/monumentos/castell-vell 20/07/2013.

CastillosNet (2011). Castillo de Montornés. http://www.castillosnet.org/programs/castillosnet.php?tip=ficcas\&dat =castellon/CS-CAS-035 20/07/2013.

Forcada Martí, V. (1992). Torres y castillos de la Provincia de Castellón. Sociedad Castellonense de Cultura, 1992.

Ferrer de Almenara, Sergio (2011). El Grao Siglo XX. ACEN.

Generalitat Valenciana (2009). Torreta Alonso. http://www.cult.gva.es/dgpa/bics/detalles_bics.asp?IdInmueble=1355 20/07/2013.

Gimeno Michavilla, Vicente (1984). Del Castellón viejo. Caja de Ahorros y Monte Piedad de Castellón.

MonumentalNet (2013). Atalaya de Montornés. http://www.monumentalnet.org/comunidad_valenciana/castellon_ castello/benicasim_benicassim/benicasim/atalaya_de_montornes.php 20/07/2013.

Patronato Provincial de Turismo de Castellón (2013). Torres de vigía o de defensa; Oropesa del Mar. http://www. castellon-costaazahar.com/103409_es/Torres-vig\%C3\%ADas-o-de-defensa-(Oropesa-del-Mar) 20/07/2013

Prades, J. E. (2012). La torre vigía de San Vicente. http://juanemilioprades.blogspot.com.es/2012/01/torre-de-sanvicente-benicasim.html.

— (2012), La torre dels Gats, La Ribera-Cabanes. Revista Mainhardtm n. ${ }^{\circ 73}$, agosto 2012. 
